Endocrinol. Japon. 1963, 10 (2), 119 124

\title{
THE EFFEGT OF THE APPLICATION OF GONADAL HORMONES ON THE RESTORATION TIME OF THE ADRENALS IN GUINEA- PIGS AFTER PROLONGED TREATMENT WITH CORTISONE
}

\author{
GERHARD WINKLER AND MARTIN HERRMANN
}

The widespread use of adrenal hormones and their synthetic derivatives in medicine was followed by the realization that many undesirable clinical sideeffects can occur following their administration. Among these, the action on what has been designated as the "feed-back" system is very important because of the functional adrenal insufficiency after long term treatment with corticosteroid hormones. There have been many attempts to counteract the medicamentous adrenal insufficiency, especially with ACTH, which have not been always successful up to now in view of the possible simultaneous blocking action of ACTH on the hypophyseal-hypothalamic control system.

Since 1950 some reports have been published on a specific action of steroids like Methylandrostenediol (Winter, 1953; Steinetz, 1961). Testosterone (Zizine et al., 1950; Hermann, 1962; Martini et al., 1963), Norandrostenolone-Propionate (Rinne et al., 1958) on the adrenals in preventing or delaying the atrophy after hypophysectomy or steroid treatment. These results were based on original experiments of Cutuly et al. (1938), confirmed by Leonard (1944) and Leathem (1944). According to Gaunt (1953) the effectiveness of these compounds is not correlated with their degree of androgenicity.

Since the clinical observations of Landau (1913), oestrogens are known to have a distinct influence on the adrenal size. Experimental evidence of the ability to cause adrenal enlargement was first given by Selye (1953), and Loeser (1939), and was subsequently confirmed by Vogt (1955).

\section{MATERIALS AND METHODS}

Our own experiments were designed to check the possibility of utilizing these observations in preventing or reducing the time of morphological atrophy or functional insufficiency of the adrenals. This shall be demonstrated in a series of three experiments involving 188 guinea-pigs. Three criteria were applied, each of them showing a different aspect of adrenal activity.

1. The first is based on the sensitivity of guinea-pigs towards the stress of intoxication by diphtheria toxin. One day after administration of this toxin the adrenals of normal, healthy animals exhibit a typical picture of macroscopically dark red glands, showing under the microscope a severe, haemorrhagic necrosis of the organ. This phenomenon does not occur in hypophysectomised animals as well as in cortisone-treated ones, which show a white-yellow color of their adrenals, so therefore it can be concluded that it is dependent on ACTH stimulation. This has been elaborated by Tonutti (1953) and Herrman and Winkler (1959) in numerous experimental conditions.

2. The second criterion utilizes the fact well known to histologists, that there is an increase in volume of metabolically active cells, especially during stimulation by a trophic hormone. That

Received for publication February 12, 1963. 
this is valid for the endocrinologically active cells of the testis, the ovary, as well as of the zona fasciculata of the adrenal cortex was shown by Tonutti (1953) and his co-workers. In the case of the guinea-pig there is an increase in size in the fasciculata cells after ACTH or stressful stimuli, but a significant decrease after hypophysectomy. The procedure of measurement involves fixation of the organ in Bouin solution, embedding in paraffin and then staining; after that the drawing of the cells by a reflected microscopic picture always of the same region of the zona fasciculata. The volume is calculated from the longest and shortest diameters applying a nomogram. It is quite obvious that this method is much more reliable than the measurement of the weight of the gland alone, as it does not vary so much regarding the age and size of the animal, and offers a greater number of data for statistical analysis as the values of at least 200 cells of each animal are measured.

3. The assay of 17-Hydroxycorticosteroids excretion (17-OHCS) was carried out by a modified Porter-Silber procedure (Liddle, 1955) in order to evaluate functional adrenal activity. Our own experiences with these methods have been published elsewhere (Winkler et al., 1962; Winkler et al., 1963). The normal values vary according to the size of the animal to about $200 \sim 300$ $\mu \mathrm{g} / \mathrm{day}$.

\section{RESULTS}

In a control group, male guinea-pigs were treated for 28 days with $5 \mathrm{mg}$ Cortisone*, which was followed by the well-known atrophy of the adrenals. In Figure 1 the values of the nuclear volume and the 17-OHCS excretion in urine are listed. After cessation of treatment the level is as low as in hypophysectomised animals; the 17-OHCS excretion is reduced too. The time of recovery, in which these values reach again their normal level, is called the "restoration time" of the adrenals. During this period there is no reaction of the hypophyseal-adrenal axis on the stress of the diphtheria-intoxication, which is strictly dependent on ACTH (Tonutti, 1953). Eight to ten days after discontinuing the treatment with cortisone the adrenals gain their normal size, and the haemorrhagic necrosis in the diphtheria-intoxication denotes the stress-induced ACTH-mobilization. Within some days the nuclear volume considerably exceeds the normal level in the socalled "rebound effect", which has been first described in rats by Kracht (1958). In former experiments we confirmed this in the case of the guinea-pig with concomitant rise of the 17-OHCS excretion, which indicates that not only is the histological picture becoming normal, but also that the functional capacity is regained (Herrmann and Winkler, 1958). In the following experiments two groups of animals were treated during a period of 4 weeks in a similar manner with $5 \mathrm{mg}$ Cortisone, one group (23 animals) receiving during the same time simultaneously $500 \mu \mathrm{g}$ of the anabolic agent Methandrostenolone, the second group (55) $100 \mu \mathrm{g}$ Oestradiol-Propionate per day. In Figure 2 the curves of the nuclear volume of the fasciculata cells are recorded. As has been shown previously, the animals

\footnotetext{
* Preparations used

1. Cortisone-SCHERING

2. Methandrostenolone $=17 \beta$-hydroxy-17 $\alpha$-methyl androsta-1,4 dien-3-one"Dianabol"-CIBA

3. Estradiol-Propionate "Ovocyclin"-CIBA
} 


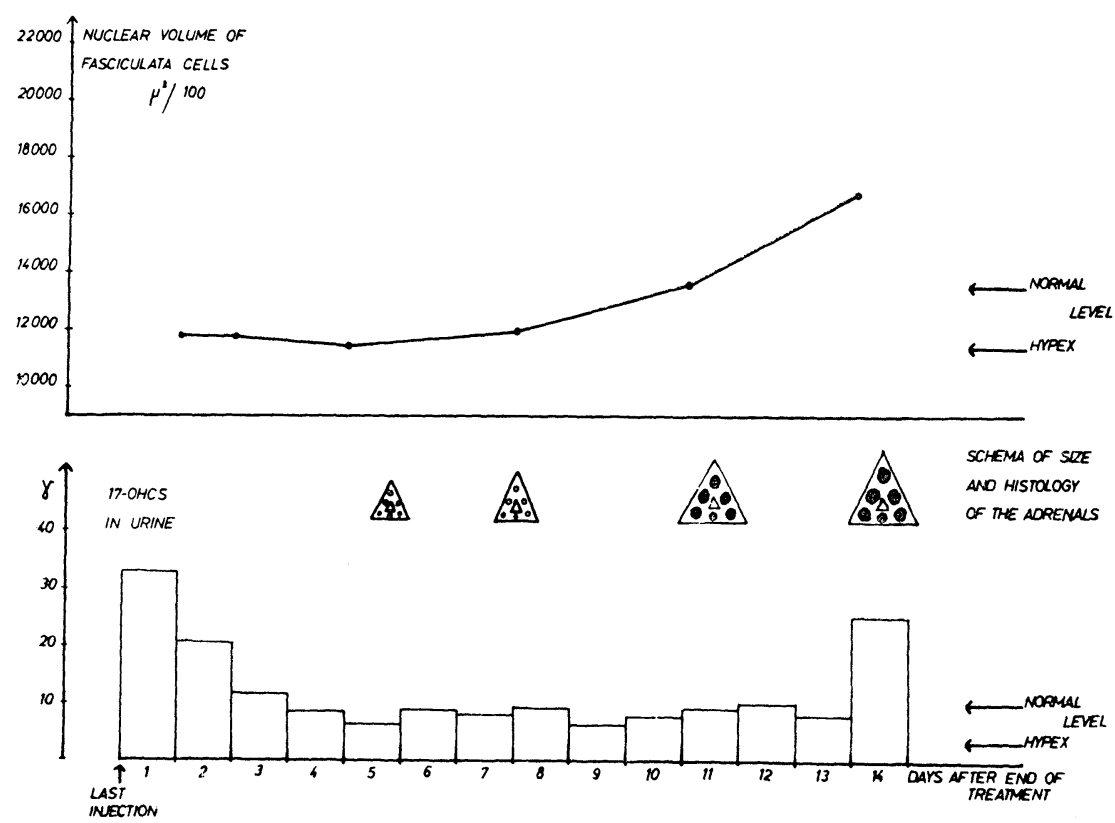

Fig. 1. (above): Nuclear volume of fasciculata cells after sacrificing the animals on day 2, 3, 5, 8, 11 and 13 after stopping Cortisone treatment

(below): 17-OHCS-excretion in urine calculated per animal/hr. on consecutive days

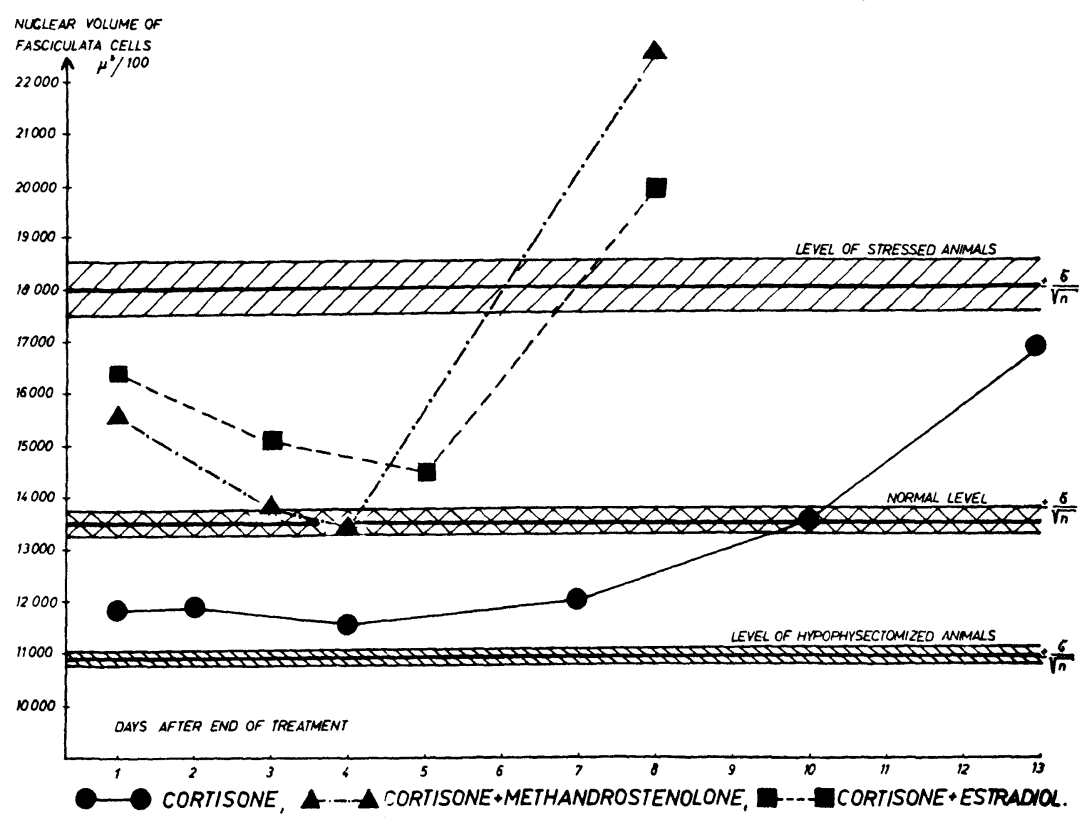

Fig. 2. Nuclear volume of fasciculata cells of animals treated with $5 \mathrm{mg}$ Cortisone, Cortisone $+0.5 \mathrm{mg}$ Methandrostenolone, Cortisone $+0.1 \mathrm{mg}$ Oestradiolproprionate after stopping treatment. 
which were treated only with Cortisone reach the normal size and nuclear volume of the adrenals not before 8 10 days after the last injection, whereas the guineapigs with Methandrostenolone and Oestrogen treatment immediately after cessation of the regimen show a more or less elevated nuclear volume associated with increased size of the adrenals. After a transient decrease there is a rapid rise within some days far beyond the normal level in the type of a modified "rebound" effect. Figure 3 shows a schematic representation of the macroscopic

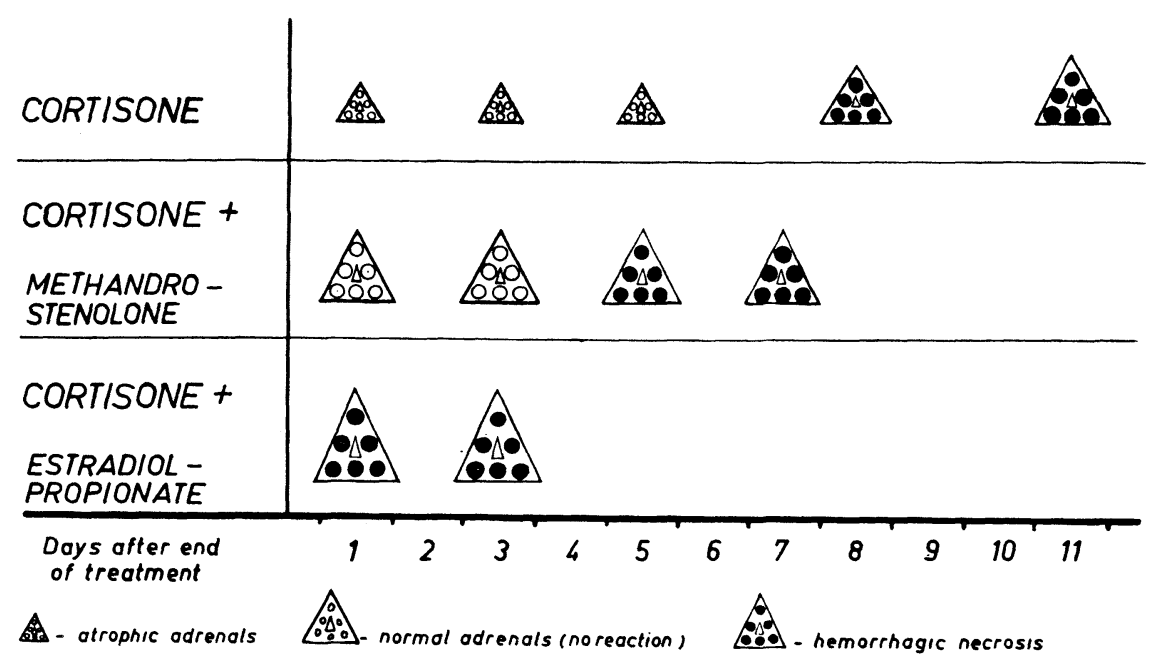

Fig. 3. Schematic representation of size and histological appearance of the adrenals of guinea-pigs in the reaction on Diphtheria-intoxication after cessation of long-term treatment with Cortisone, Cortisone + Methandrostenolone and Cortisone + OestradiolPropionate

changes and histological features of the adrenals after the stress of diphtheriaintoxication. In the first line one can see that the size of the adrenals of the animals receiving Cortisone alone after cessation of treatment increases gradually as well as the nuclear volume, until on the 8 th $\sim 10$ th day the haemorrhagic necrosis occurs, probably indicating abundant ACTH secretion. The second line shows that in Methandrostenolone-treated animals the size and the nuclear volume are within the normal range, but higher than in animals receiving Cortisone alone, and the adrenals appear to be responsive on the 5th day onward.

The third row demonstrates the enlarged adrenals of the Oestrogen-treated animals despite the cortisone medication. The haemorrhagic necrosis occurs immediately after the last injection of the mixture. The 17-OHCS excretion remains low until the 18 th $\sim 20$ th day after stopping the treatment, and then returns to the normal level. 


\section{DISGUSSION}

From the results presented here, there seems to be sufficient evidence that the rapidly increasing nuclear volume, as well as the earlier reaction of the enlarged adrenals to the stress reaction of diphtheria-intoxication in the Methandrostenolone- and Oestrogen-treated animals, must be regarded as proof for an intact pituitary-adrenal axis with sufficient ACTH-mobilization. This is in accordance with the results of Wallace et al. (1957), who found an augmented ACTH-responsiveness in man after ethynyloestradiol application. Recently Kitay (1962) also demonstrated an increased ACTH-content of the pituitary in rats after oestrogen administration, while treatment with Cortisone alone resulted in a significant reduction in pituitary ACTH associated with a failure to discharge ACTH in response to stress. Simultaneous treatment with oestrogens in such animals was found to increase pituitary ACTH levels at rest and to enhance ACTH-release after stress.

An augmented Cortisol-binding capacity of the blood proteins after oestrogen treatment has been demonstrated in the experiments of Sandberg (1959), Mills (1960), Peterson (1960), and Daughaday (1961); as the protein-bound Cortisol is presumably biologically inactive, there is no alteration of ACTH-mobilization as has been previously shown in pregnancy. An increased or altered Corticosteroid metabolism can therefore be assumed, as has been suggested by most authors, particularly when the discrepancy between low corticosteroid secretion and enlarged adrenals was observed (Vogt, 1955; Clayton, 1957). The mode of action may be due to an interaction in the synthesis of corticosteroids, probably in competition at enzymic level. This assumption is supported by the findings of McKearns and Kaleita (1960), who demonstrated a blocking action of oestrogens on the adrenal enzyme glucose-6-phosphodehydrogenase, which has been stated by Studzinsky et al. (1962) to be important in corticosteroid biosynthesis. Because of the evidence for a metabolic degradation of methandrostenolone to oestrogens (Breuer, 1962), the comparable actions of both substances in our experiments could easily be understood. The mammogenic properties of methandrostenolone (Laron, 1962; Ahren et al., 1963) may serve as additional proof of this hypothesis.

In conclusion, the simultaneous application of anabolic agents and sex hormones during corticosteroid treatment is recommended in order to avoid this type of side effect in clinical practise.

\section{SUMMARY}

1. 28-days treatment with $5 \mathrm{mg}$ Cortisone daily produces in guinea-pigs the wellknown atrophy of the adrenals, associated with a low nuclear volume of the fasciculata cells of the adrenal cortex and a decreased 17-OHCS excretion in urine, comparable to hypophysectomized animals. Eight to ten days after discontinuing the Cortisone treatment, during which period there is no reaction to stressful stimuli, the reduced levels increase and exceed its previous values in the so called "Rebound-phenomenon". 
2. After simultaneous treatment with $0.1 \mathrm{mg}$ Oestradiol-proprionate or $0.5 \mathrm{mg}$ Methandrostenolone respectively the adrenal atrophy can be prevented and the reaction to stress seems to occur earlier than in animals treated with Cortisone only. The 17-OHCS excretion remains low, possibly because of metabolic alterations.

\section{REFERENCES}

Ahren, K., A. Arvill and A. Hjalmarson (1963). Acta Endocrinol. 42, 601.

Breuer, H. Personal communication.

Clayton, B. and J.E. Hammant (1957). J. Endocrinol. 15, 255.

Cutuly, E., E. Cutuly and D. McCullagh (1938). Proc. Soc. Exptl. Biol. Med. 38, 818.

Daughaday, W.H., J. Holloszy and I.K. Mariz (1961). J. Clin. Endocrinol. and Metabolism 21, 53.

Gaunt, R., C.H. Tuthill, N. Antonchak and J.H. Leathem (1953). Endocrinology 52, 407.

Herrmann, M. (1962). Z. mikr. anat. Forsch. 68, 293.

Herrmann, M. and G. Winkler (1958). Die Naturwissenschaften 45, 267.

Herrmann, M. and G. Winkler (1959). Acta Neuroveget. 20, 38.

Kitay, J. Intern. Sympos. Horm. Steroids Milan (1962).

Kracht, J. (1958). Endokricologie 35, 290.

Landau, M. Die Nebennierenrinde, Verlag Gustav Fischer, Jena (1913).

Laron, Z. (1962). J. Clin. Endocrinol. 22, 450.

Leathem, J.H. (1944). Anat. Rec. 89, 155.

Leonard, S.L. (1944). Endocrinology 35, 82.

Liddle, G., J. Richards and R. Peterson (1955). Ibid. 57, 594.

Loeser, A. (1939). Z. ges. Exp. Med. 105, 430.

McKearns, K.W. and E. Kaleita (1960). Biochem. Biophys. Res. Com. 2, 344.

Mills, I.H., H.P. Schedl, P.S. Chen and F.C. Bartter (1960). J. Clin. Endocrinol. Metabolism 20, 515.

Peterson. R.E., G. Nokes, P.S. Chen and R.L. Black (1960). Ibid. 20, 495.

Rinne, U.K. and E.K. Häätänen (1958). Acta Endocrinol. 27, 423.

Sandberg, A.A. and W.R. Slaunwhite (1959). J. Clin. Invest. 38, 1290.

Selye, H. and J.B. Collip (1935). Proc. Soc. Exptl. Biol. Med. 32, 283.

Steinetz, B.G. and J.H. Leathem (1961). Ibid. 108, 113.

Studzinski, G.P., T. Symington and J.K. Grant (1962). Acta Endcrinol. 40, 232.

Tonutti, E. (1953). Verhandl. deut. Ges. Pathol. 36, 123.

Vogt, M. (1955). J. Physiol. 128, 7.

Wallace, E., H.I. Silverberg and A.C. Carter (1957). Proc. Soc. Exptl. Biol. Med. 95, 805.

Winkler, G., M. Herrmann, R. Blobel and E. Tonutti (1962). Endokrinologie 43, 219.

Winkler, G., M. Herrmann, R. Blobel and E. Tonutti (1963). Ibid. (In press)

Winter, G.A., H.L. Hollings and R.B. Stebbins (1953). Endocrinology 52, 123.

Zizine, L.A., M.E. Simpson and H.E. Evans (1950). Ibid. 47, 97. 